\title{
HIRARKI
}

Jurnal Ilmiah Manajemen dan Bisnis

http://journal.upp.ac.id/index.php/Hirarki

\section{ANALISIS MINAT MENGGUNAKAN MOBILE PAYMENT DENGAN PENDEKATAN TECHNOLOGY ACCPETANCE MODEL PADA PENGGUNA LINK AJA SUKABUMI}

Rayhan Ar Rasyid, Erry Sunarya, Asep M Ramdan

Ilmu Administrasi Bisnis, Universitas Muhammadiyah Sukabumi, Kota Sukabumi, Indonesia

\section{Info Artikel}

Sejarah Artikel:

Diterima : 1 Juni 2020

Disetujui : 15 Juni 2020

Dipublikasikan : 30 Juni

2020

Keywords:

Financial Technology,

Technology Aceptence

Model, Mobile Payment

\begin{abstract}
Abstrak
Pemerintah Republik Indonesia melalui Bank Indonesia sejak 14 Agustus 2014 telah mencanangkan Gerakan Nasional Non Tunai (GNNT) dengan tujuan untuk meningkatkan kesadaran masyarakat dalam penggunaan instrumen nontunai, sehingga seiring waktu akan terbentuk suatu komunitas atau masyarakat transaksi nontunai (Less Cash Society / LCS) dengan menggunakan instrumen nontunai dalam kegiatan ekonominya (Bank Indonesia, 2014) disamping itu Gubernur BI juga telah mengeluarkan regulasi baru tentang e-Money No.18/17/PBI/2016 yang isiny a mengatur tentang peredaran uang electronik maupun layanan keuangan digital (LKD) kepada masyarakat. Technology Acceptance Model, Model penerimaan teknologi (TAM) adalah sebuah model untuk menilai apakah sebuah teknologi dapat diterima/tidak oleh masyarakat baik secara individu. (Tatjana, 2016). Hasil dari penelitian ini menjelaskan bahwa variabel-variabel TAM secara signifikan berpengaruh terhadap minat menggunakan teknologi.
\end{abstract}

\section{MOBILE PAYMENT USAGE INTENTION THROUGH TECHNOLOGY ACCEPTANCE MODEL AT LINKAJA USERS SUKABUMI}

\begin{abstract}
The Government of the Republic of Indonesia through Bank Indonesia since August 14, 2014 has launched the National Non-Cash Movement (GNNT) with the aim of increasing public awareness in the use of non-cash instruments, so that over time a community or non-cash transaction community (LCS) will be formed using non-cash instruments in its economic activities (Bank Indonesia, 2014) in addition to that the Governor of BI has also issued a new regulation on e-Money No.18 / 17 / PBI / 2016 whose contents regulate the circulation of electronic money and digital financial services (DFS) to the public. Technology Acceptance Model, Technology acceptance model (TAM) is a model to assess whether a technology can be accepted / not by the community either individually. (Tatjana, 2016). The results of this study explain that the TAM variables significantly influence the interest in using technology.
\end{abstract}

\footnotetext{
Alamat korespondensi :

Universitas Muhamadiyah Sukabumi

E-mail: rayhanipsdua@gmail.com
} 


\section{PENDAHULUAN}

Perkembangan mobile payment atau pembayaran bergerak di Indonesia telah dimulai sejak tahun 2007 dengan diluncurkannya salah satu aplikasi pembayaran bergerak oleh PT Telkomsel Indonesia yaitu Telkomsel Cash. Disusul pada tahun 2008 dengan diluncurkannya aplikasi Dompetku. Pada tahun 2010 ke-atas barulah aplikasi pembayaran bergerak (mobile payment) banyak diluncurkan.

Pemerintah Republik Indonesia melalui Bank Indonesia sejak 14 Agustus 2014 telah mencanangkan Gerakan Nasional Non Tunai (GNNT) dengan tujuan untuk meningkatkan kesadaran masyarakat dalam penggunaan instrumen nontunai, sehingga seiring waktu akan terbentuk suatu komunitas atau masyarakat transaksi nontunai (Less Cash Society / LCS) dengan menggunakan instrumen nontunai dalam kegiatan ekonominya) disamping itu Gubernur BI juga telah mengeluarkan regulasi baru tentang eMoney No.18/17/PBI/2016 yang isinya mengatur tentang peredaran uang electronik maupun layanan keuangan digital (LKD) kepada masyarakat.(Bank Indonesia, 2014)

Menurut data Asosiasi Fintech Indonesia (Aftech) per Desember 2017, dari 235 perusahaan fintech aktif, 39\%nya bergerak di subsektor sistem transaksi (payment). Institusi perbankan adalah institusi paling aktif dalam melakukan kolaborasi dengan fintech. Menurut Aftech, 63,90\% pelaku fintech telah terkoneksi ke sistem perbankan. Sebanyak 77\% di antaranya melakukan kolaborasi langsung dengan perbankan. (Kompas, 2018)

Jumlah pengguna mobile payment di Indonesia sudah mencapai sekitar 40 juta pengguna (MDI Ventures \& Mandiri
Sekuritas : 2018) tentunya angka ini menunjukkan pertumbuhan yang sangat pesat. Jumlah ini juga berarti sektiar $40 \%$ dari pengguna internet di Indonesia telah menggunakan mobile payment sebagai alat transaksi.

Pada bulan Januari tahun 2019 PT. Telkomsel bersama Himpunan Bank Miliki Negara (HIMBARA) memutuskan untuk meluncurkan platform pembayaran elektronik baru berbasis QR yanag bernama Link Aja. Keputusan tersebut membuat Telkomsel Cash harus melebur menjadi Link Aja mulai awal Februari 2019.

LinkAja beroperasi di bawah PT Fintek Karya Nusantara (Finarya) yang merupakan bentukan 7 BUMN yaitu PT Telkomsel, PT Bank Rakyat Indonesia (Persero) Tbk, PT Bank Nasional Indonesia (Persero) Tbk, PT Bank Mandiri (Persero) Tbk, PT Bank Tabungan Negara (Persero) Tbk, PT Pertamina (Persero) dan PT Asuransi Jiwasraya (Persero). Menteri BUMN Rini Soemarno mengatakan, LinkAja memiliki misi untuk memberikan akses layanan keuangan kepada masyarakat Indonesia. Kehadiran LinkAja juga diharapkan bisa meningkatkan inklusi keuangan dan menyukseskan Gerakan Nasional Non Tunai (GNNT). "Rendahnya inklusi keuangan di Indonesia salah satunya disebabkan karena masyarakat masih memilih bertransaksi secara tunai," ungkap Rini di Gelora Bung Karno, Jakarta, Minggu (30/6). (Dewi Rachmat Kusuma, 2019)

Minat menggunakan sebuah teknologi merupakan hal penting yang harus dimiliki oleh masyarakat sebelum nantinya memutuskan apakah akan menggunakan teknologi tersebut atau tidak. Tanpa adanya minat maka masyarakat enggan untuk menggunakan sebuah teknologi. Terlebih lagi setelah mencoba untuk 
menggunakan teknologi tersebut masyarakat nantinya akan memutuskan apakah ia akan tetap menggunakan teknologi tersebut, atau beralih pada teknologi lain.

Menurut perspektif Techonology Acceptance Model (TAM) Sikap terhadap penggunaan teknologi merupakan salah satu faktor yang memengaruhi Minat masyarakat untuk menggunakan sebuah teknologi. Dalam penentuan sikap terhadap penggunaan sebuah teknologi masyarakat harus merasakan terlebih dahulu bahwa adanya teknologi ini merupakan sesuatu hal yang positif. Teknologi baru ini haruslah dirasa positif terlebih dahulu oleh masyarakat, sebelum nantinya masyarakat memutuskan ingin menggunakan atau tidaknya. Selain feeling masyarakat yang positif terhadap teknologi baru yang ditawarkan, masyarakat juga harus merasakan kepuasan dan merasakan bahwa tekonologi baru yang ditawarkan membantu masyarakat dalam kegiatan sehari-harinya.

Fishbein (2014) menyatakan, kegunaan dari sebuah teknologi menjadi faktor yang memengaruhi sikap masyarakat terhadap penggunaan teknologi. Semakin dirasa kegunaannya oleh masyarakat maka masyarakat akan semakin merasakan dampak positif dari sebuah teknologi. Dari berbagai aspek kegunaan sebuah teknologi ini dapat ditinjau, diantaranya adalah efektivitas teknologi dalam membantu kegiatan masyarakat, kemudian efisiensi waktu yang diberikan ketika masyarakat menggunakan teknologi tersebut, dan sejauhmana teknologi tersebut membantu masyarakat dalam kegiatannya.

Semakin mudah teknologi itu dipahami, dipelajari digunakan dan akhirnya masyarakat mudah terampil menggunakan teknologi tersebut, maka masyarakat akan semakin nyaman dengan sebuah teknologi baru yang ditawarkan. Fishbein (2014) menyatakan kemudahan penggunaan inilah yang menjadi faktor pendamping kegunaan sebuah teknologi untuk memengaruhi sikap masyarakat terhadap sebuah teknologi. Ajeng (2018) menyatakan Perceived ease of use juga memegaruhi minat masyarakat menggunakan teknologi.

sTatjana (2016) menyatakan Technology Acceptance Model, Model penerimaan teknologi (TAM) adalah sebuah model untuk menilai apakah sebuah teknologi dapat diterima/tidak oleh masyarakat baik secara individu. Model Penerimaan Teknologi TAM awalnya diadaptasi dari teori beralasan tindakan (TRA) dari Ajzen dan Fishbein pada tahun 1980 untuk menjelaskan minat individu untuk menerima teknologi informasi baru. Davis (1989) menyatakan TAM berpendapat bahwa kegunaan yang dirasakan adalah penilaian subyektif individu untuk meningkatkan kinerjanya sendiri, personal kesejahteraan atau utilitas yang ditawarkan oleh teknologi

1) Perceived Ease Of Use

Davis (1989) menyatakan ease (memudahkan) artinya "freedom from difficulty or great effort" atau kebebasan dari kesulitan atau usaha keras". Selanjutnya "ease to use perceived" didefinisikan "the degree to which a person believes that using a particular system would be free of effort" artinya kemudahan untuk menggunakan dirasakan didefinisikan sejauh mana seseorang percaya bahwa menggunakan sistem tertentu akan bebas dari usaha".

Adapun dimensi kemudahan penggunaan menurut (Davis, 1989) 
(a) Mudah dipelajari (easy to learn),

(b) Dapat dikontrol (controllable)

(c) Jelas \& dapat dipahami (clear \& understandable) (d) Fleksibel (flexible) (e) Mudah untuk menjadi terampil/mahir (easy to become skillful) (f) Mudah digunakan (easy to use)

2) Perceived Usefulness

Davis (1989) menyatakan

Perceived Usefulness (kegunaan) didefinisikan sebagai sejauh mana seseorang percaya bahwa menggunakan suatu teknologi akan meningkatkan kinerja pekerjaannya "as the extent to which a person believes that using a technology will enhance her or his performance".

Davis (1989) menjabarkan indikator daripada perceived usefulness yang terdiri dari :

(a) Mempercepat pekerjaan (work more quickly) (b) Meningkatkan

kinerja (improve job performance) (c) Meningkatkan produktivitas (increase productivity) (d) Efektifitas (effectiveness) (e) Mempermudah pekerjaan (make job easier) Bermanfaat (useful)

\section{3) Attitude Towards Using}

Davis (1989) menyatakan Attitude Towards Using (sikap terhadap penggunaan) didefinisikan sebagai perasaan perasaan positif atau negatif dari seseorang jika harus melakukan perilaku yang akan ditentukan "an individual's positive or negative feelings about performing the target behavior".

Sedangkan Mathieson

mendefinisikan sikap terhadap attitude towards behavior (perilaku) sebagai evaluasi pemakai tentang ketertarikannya menggunakan sistem "the user's evaluation of the desirability of his or her using the system".
Dimensi - dimensi attitude towards using menurut Chauhan (2015) yaitu :

(a) Favorable Attitude; sikap yang menguntungkan. (b) Benefical; bermanfaat. (c) Idea of Transaction; ide bertransaksi

\section{4) Behavior Intention to Use}

Davis (1989) menyatakan Minat perilaku pengguna merupakan betuk sikap atau perilaku yang cenderung untuk tetap menggunakan suatu teknologi

Menurut (Rakhmad S, Astuti, \& Susilo, 2012) dimensi variabel dari Behavioral Intention to Use adalah :

(a) Minat untuk menggunakan (b) Minat untuk meningkatkan penggunaan (c) Memotivasi ke pengguna lain

\section{METODE}

Metode yang digunakan dalam penelitian ini adalah metode deskriptif asosiatif. Pengertian metode deskriptif menurut (Sugiyono, 2013) yaitu

"Suatu rumusan masalah yang berkenaan dengan pertanyaan terhadap keberadaan variabel mandiri, baik hanya pada satu variabel atau lebih (variabel mandiri adalah variabel yang berdiri sendiri, bukan variabel independen, karena variabel independen selalu dipasangkan dengan variabel dependen)."

Sedangkan metode asosiatif menurut Sugiyono (2016) adalah sebagai berikut:

"Penelitian asosiatif merupakan penelitian yang bertujuan untuk mengetahui hubungan dua variabel atau lebih. Dalam penelitian ini maka akan dapat dibangun suatu teori yang dapat berfungsi untuk menjelaskan, 
meramalkan dan mengontrol suatu gejala."

Menurut Sugiyono (2016) menyatakan bahwa paradigma penelitian dapat diartikan sebagai berikut :

"Pola pikir yang menunjukkan hubungan antara variabel yang akan diteliti yang sekaligus mencerminkan jenis dan jumlah rumusan masalah yang perlu dijawab melalui penelitian, teori yang digunakan untuk merumuskan hipotesis, jenis dan jumlah hipotesis, dan teknik analisis statistik yang akan digunakan".

Pada penelitian ini, paradigma penelitian yang digunakan oleh peneliti yaitu menggunakan paradigma ganda dengan dua variabel independen dan satu variabel dependen, adapun paradigma penelitian ini dapat digambarkan adalah sebagai berikut:

\section{HASIL DAN PEMBAHASAN}

Analisis jalur yang pertama akan meneliti jalur 1 yaitu menghitung pengaruh variabel perceived ease of use (X1) terhadap perceived usefulness (X2). Hasil dari uji pengaruh tersebut dapat dilihat pada tabel di atas. Nilai standardized coefficient beta X1 terhadap X2 sebesar 0,903. Sedangkan untuk nilai epsilon 1 dicari menggunakan rumus e $=\mathrm{V} 1-\mathrm{R}^{2}$. Adapun hasil $\mathrm{R}^{2}$ atau koefisien determinasi dapat dilihat pada tabel 1. Model Summary didapat nilai $\mathrm{R}$ Square sebesar 0,816 artinya nilai epsilon 1 adalah V1-0,816 yaitu sebesar 0,428.

Analisis jalur yang kedua akan meneliti jalur 2 yaitu menghitung pengaruh variabel perceived ease of use (X1) dan perceived usefulness (X2) tehradap attitude towards using (X3). Hasil dari uji pengaruh tersebut dapat dilihat pada tabel di atas. Nilai standardized coefficient beta atau koefisien X1 terhadap X3 sebesar 0.209. Untuk nilai standardized coefficient beta atau koefisien X2 terhadap X3 sebesar 0.739. Sedangkan untuk nilai epsilon 1 dicari menggunakan rumus e $=\mathrm{V} 1-\mathrm{R} 2$. Adapun hasil R2 atau koefisien determinasi dapat dilihat pada tabel 2 . Model Summary didapat nilai R Square sebesar 0,869 artinya nilai epsilon 2 adalah V(1-0,869 )yaitu sebesar 0,362.

Analisis jalur yang ketiga akan meneliti jalur 3 yaitu menghitung pengaruh variabel perceived ease of use (X1), perceived usefulness (X2) dan attitude towards using (X3) terhadap behavior intention to use (Y). Hasil dari uji pengaruh tersebut dapat dilihat pada tabel di atas. Nilai standardized coefficient beta atau koefisien X1 terhadap Y sebesar 0,102 X2 terhadap $Y$ sebesar 0.290. Untuk nilai standardized coefficient beta atau koefisien X3 terhadap Y sebesar 0.532. Sedangkan untuk nilai epsilon 1 dicari menggunakan rumus $\mathrm{e}=\mathrm{V} 1-\mathrm{R} 2$. Adapun hasil R2 atau koefisien determinasi dapat dilihat pada tabel 3. Model Summary didapat nilai R Square sebesar 0,787 artinya nilai epsilon 3 adalah V(1-0,787 )yaitu sebesar 0,461 . Maka dari hasil tersebut didapat hasil sebagaimana gambar 1 Uji Hipotesis

Uji T (Parsial)

Uji $t$ (parsial) ini digunakan untuk membuktikan pengaruh antara variabel independen terhadap variabel dependen. Dimana apabila thitung > ttabel maka menunjukkan bahwa hipotesis yang diajukan diterima. Nilai $t$ hitung dapat dilihat pada hasil regresi dan nilai $\mathrm{t}$ tabel didapat melalui sig. $\mathrm{a}=$ 0,05 dengan $\mathrm{df}=\mathrm{n}-\mathrm{k}$.

H1 : perceived ease of use berpengaruh terhadap perceived usefulness. 
Hasil uji t antara perceived ease of use terhadap perceived usefulness dapat dilihat pada tabel 4 Berdasararkan data diolah variabel perceived ease of use memberikan hasil t sebesar 30.294 yang lebih besar dari nilai $t$ tabel sebesar 1.652 (nilai t tabel didapat dari tabel t). Dapat disimpulkan bahwa thitung $>t$ tabel. Kemudian nilai signifikansi menunjukkan angka 0,000. Jadi dapat ditarik kesimpulan bahwa variabel perceived ease of use berpengaruh terhadap variabel perceived usefulness.

H2 : perceived ease of use berpengaruh terhadap attitude towards using.

Hasil uji $t$ antara perceived ease of use, perceived usefulness terhadap attitude towards using dapat dilihat pada tabel 5 .

Berdasararkan data diolah variabel perceived ease of use memberikan hasil t sebesar 3.545 yang lebih besar dari nilai $t$ tabel sebesar 1.652. Dapat disimpulkan bahwa $t$ hitung > $\mathrm{t}$ tabel. Kemudian nilai signifikansi menunjukkan angka 0,000. Jadi dapat ditarik kesimpulan bahwa variabel perceived ease of use berpengaruh terhadap variabel attitude towards using.

H3 : perceived usefulness berpengaruh terhadap attitude towards using

Berdasararkan data diolah variabel perceived usefulness memberikan hasil $\mathrm{t}$ sebesar 12.566 yang lebih besar dari nilai $t$ tabel sebesar 1.652. Dapat disimpulkan bahwa thitung > t tabel. Kemudian nilai signifikansi menunjukkan angka 0,000. Jadi dapat ditarik kesimpulan bahwa variabel perceived usefulness memberikan pengaruh positif terhadap variabel attitude towards using.
Dari hasil pengujian tersebut, dapat disimpulkan bahwa H3 yang menjelaskan perceived usefulness berpengaruh terhadap attitude towards using pada masyarakat Kota Sukabumi dalam menggunakan aplikasi pembayaran bergerak Link Aja terbukti. Sehingga apabila perceived usefulness dari Link Aja meningkat maka attitude towards using dari masyarakat Kota Sukabumi terhadap Link Aja pun akan meningkat.

H4 : perceived ease of use berpengaruh pada behavior intention to use

Hasil uji t antara perceived ease of use, perceived usefulness dan attitude towards using terhadap behavior intention to use dapat dilihat pada tabel 6

Berdasararkan data diolah variabel perceived ease of use memberikan hasil t sebesar 3.880 yang lebih besar dari nilai $t$ tabel sebesar 1.652. Dapat disimpulkan bahwa $\mathrm{t}$ hitung $>\mathrm{t}$ tabel. Kemudian nilai signifikansi menunjukkan angka 0,000. Jadi dapat ditarik kesimpulan bahwa variabel perceived usefulness memberikan pengaruh positif terhadap variabel behavoioural intention to use.

H5 : perceived usefulness berpengaruh pada behavior intention to use

Berdasararkan data diolah variabel perceived usefulness memberikan hasil t sebesar 1.054 yang lebih kecil dari nilai $t$ tabel sebesar 1.652. Dapat disimpulkan bahwa $t$ hitung < t tabel. Kemudian nilai signifikansi menunjukkan angka 0,293. Jadi dapat ditarik kesimpulan bahwa variabel perceived usefulness tidak memberikan pengaruh positif terhadap variabel behavoior intention to use.

H6 : Attitude towards using berpengaruh behavior intention to use 
Berdasararkan data diolah variabel attitude towards using.memberikan hasil t sebesar 6.202 yang lebih besar dari nilai t tabel sebesar 1.652. Dapat disimpulkan bahwa t hitung $>\mathrm{t}$ tabel. Kemudian nilai signifikansi menunjukkan angka 0,000. Jadi dapat ditarik kesimpulan bahwa variabel attitude towards using memberikan pengaruh positif terhadap variabel behavior intention to use.

\section{Mediasi}

H7 :Sikap memediasi pengaruh kemudahan penggunaan terhadap minat menggunakan

Pengaruh perceived ease of use secara tidak langsung terhadap behavior intention to use dimediasi oleh attitude towards using. Untuk menghitung pengaruh tidak langusng perceived ease of use terhadap behavior intention to use oleh attitude towards using adalah dengan cara mengalikan beta X1 terhadap X3 dan beta X3 terhadap Y yaitu $0,209 \times 0,532=0,118$. Sedangkan pengaruh langsung perceived ease of use terhadap behavior intention to use adalah sebesar 0,290. Maka pengaruh total yang diberikan oleh perceived ease of use terhadap attitude towards using adalah 0,118 $+0,290=0,408$. Berdasarkan hasil penghitungan diatas dapat diambil kesimpulan bahwa attitude towards using tidak memediasi variabel perceived ease of use terhadap behavior intention to use. H8 :Sikap memediasi pengaruh kegunaan tehadap minat menggunakan Pengaruh perceived usefulness secara tidak langsung terhadap behavior intention to use dimediasi oleh attitude towards using. Untuk menghitung pengaruh tidak langusng perceived usefulness terhadap behavior intention to use oleh attitude towards using adalah dengan cara mengalikan beta $\mathrm{X} 2$ terhadap X3 dan beta X3 terhadap Y yaitu $0,739 \times 0,532=0,393$. Sedangkan pengaruh langsung perceived usefulness terhadap attitude towards using sebesar 0,102. Maka pengaruh total yang diberikan oleh perceived usefulness terhadap attitude towards using adalah 0,393 $+0,102=0,495$. Berdasarkan hasil penghitungan diatas dapat diambil kesimpulan bahwa variabel attitude towards using memediasi perceived usefulness terhadap behavior intention dikarenakan pengaruh tidak langsung > daripada pengaruh langsung.

Tabel 1

Model Summary

\begin{tabular}{|c|c|c|c|c|}
\hline \multicolumn{5}{|c|}{-2} \\
\hline Model & $\mathrm{R}$ & R Square & $\begin{array}{c}\text { Adjusted R } \\
\text { Square }\end{array}$ & $\begin{array}{l}\text { Std. Error of } \\
\text { the Estimate }\end{array}$ \\
\hline 1 & $903^{a}$ & .816 & .815 & 2.82220 \\
\hline
\end{tabular}


a. Predictors: (Constant), X1

Sumber : Hasil Penelitian, Diolah, 2020

Tabel 2

Model Summary

\begin{tabular}{cc|r|r|r} 
& & \multicolumn{2}{|c|}{ Adjusted R } & $\begin{array}{c}\text { Std. Error of } \\
\text { Model }\end{array}$ \\
\hline 1 & R & R Square & \multicolumn{1}{c}{ Square } & the Estimate \\
\hline & $.932^{\mathrm{a}}$ & .869 & .867 & 1.22951 \\
\hline
\end{tabular}

a. Predictors: (Constant), X2, X1

Sumber : Hasil Penelitian, Diolah, 2020

Tabel 3

Model Summary

\begin{tabular}{|c|c|c|c|c|}
\hline \multicolumn{5}{|c|}{ 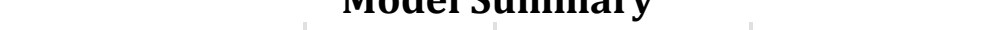 } \\
\hline Model & $\mathrm{R}$ & R Square & $\begin{array}{c}\text { Adjusted R } \\
\text { Square }\end{array}$ & $\begin{array}{l}\text { Std. Error of } \\
\text { the Estimate }\end{array}$ \\
\hline 1 & $.895^{\mathrm{a}}$ & .802 & .799 & 1.44707 \\
\hline
\end{tabular}

a. Predictors: (Constant), X2, X1, X3

Sumber : Hasil Penelitian, Diolah, 2020

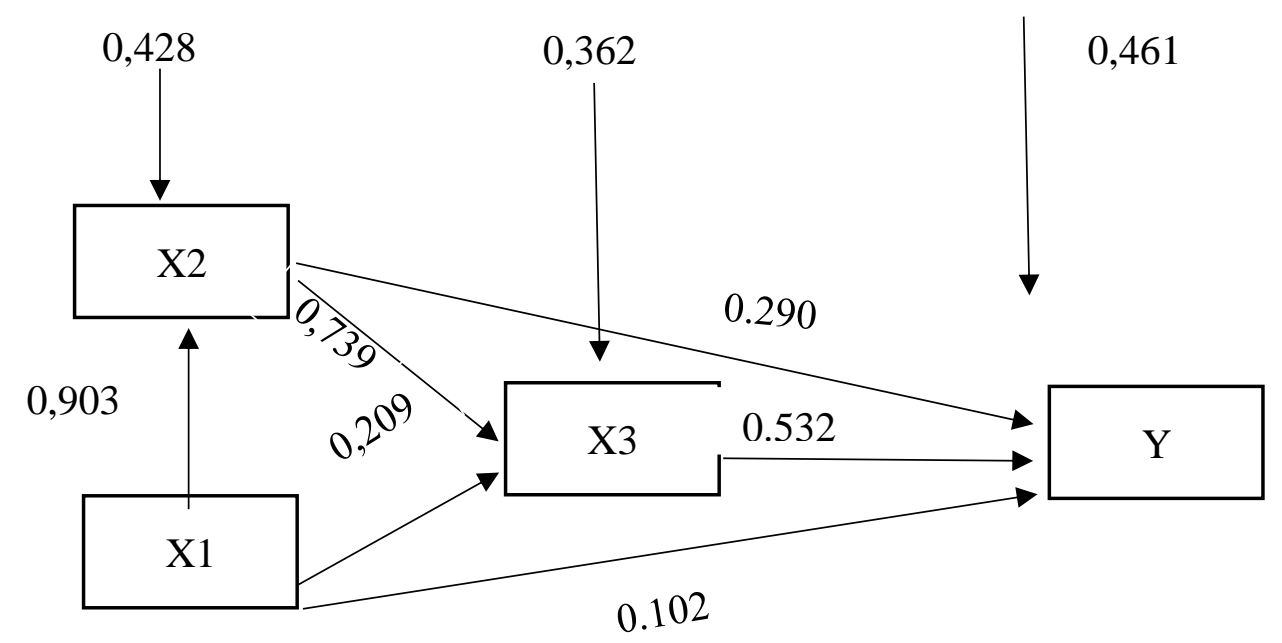

Tabel 4 Koefisien Korelasi X1 dan X2

\begin{tabular}{|c|c|c|c|c|c|c|}
\hline \multirow{2}{*}{\multicolumn{2}{|c|}{ Model }} & \multicolumn{2}{|c|}{$\begin{array}{l}\text { Unstandardized } \\
\text { Coefficients }\end{array}$} & \multirow{2}{*}{$\begin{array}{c}\text { Standardize } \\
\mathrm{d} \\
\text { Coefficients } \\
\text { Beta } \\
\end{array}$} & \multirow[b]{2}{*}{$\mathrm{t}$} & \multirow[b]{2}{*}{ Sig. } \\
\hline & & $\mathrm{B}$ & Std. Error & & & \\
\hline 1 & $\begin{array}{c}\text { (Constant } \\
\text { ) }\end{array}$ & 1.022 & .678 & & 1.508 & .133 \\
\hline & $\mathrm{X} 1$ & .965 & .032 & .903 & 30.294 & .000 \\
\hline
\end{tabular}

a. Dependent Variable: X2 
Tabel 5 Koefisien Korelasi X1, X2 dan X3

\section{Coefficients $^{\mathrm{a}}$}

\begin{tabular}{|c|c|c|c|c|c|c|}
\hline & \multirow[b]{2}{*}{ Model } & \multicolumn{2}{|c|}{$\begin{array}{l}\text { Unstandardized } \\
\text { Coefficients }\end{array}$} & \multirow{2}{*}{$\begin{array}{c}\text { Standardize } \\
\mathrm{d} \\
\text { Coefficients } \\
\text { Beta } \\
\end{array}$} & \multirow[b]{2}{*}{$\mathrm{t}$} & \multirow[b]{2}{*}{ Sig. } \\
\hline & & $\mathrm{B}$ & Std. Error & & & \\
\hline \multirow[t]{3}{*}{1} & $\begin{array}{c}\text { (Constant } \\
\text { ) }\end{array}$ & -.188 & .297 & & -.634 & .527 \\
\hline & $\mathrm{X} 1$ & .115 & .032 & .209 & 3.545 & .000 \\
\hline & $\mathrm{X} 2$ & .381 & .030 & .739 & 12.566 & .000 \\
\hline
\end{tabular}

a. Dependent Variable: X3

Sumber : Hasil Penelitian, Diolah, 2020

Tabel 6 Koefisien Korelasi X1, X2, X3 dan Y

\section{Coefficients $^{\mathbf{a}}$}

\begin{tabular}{|c|c|c|c|c|c|c|}
\hline \multirow{2}{*}{\multicolumn{2}{|c|}{ Model }} & \multicolumn{2}{|c|}{$\begin{array}{l}\text { Unstandardized } \\
\text { Coefficients }\end{array}$} & \multirow{2}{*}{$\begin{array}{c}\text { Standardize } \\
\mathrm{d} \\
\text { Coefficients } \\
\text { Beta } \\
\end{array}$} & \multirow[b]{2}{*}{$\mathrm{t}$} & \multirow{3}{*}{$\begin{array}{l}\text { Sig. } \\
.104\end{array}$} \\
\hline & & $\mathrm{B}$ & Std. Error & & & \\
\hline \multirow[t]{4}{*}{1} & $\begin{array}{c}\text { (Constant } \\
\text { ) }\end{array}$ & .571 & .350 & & 1.631 & \\
\hline & $\mathrm{X} 1$ & .152 & .039 & .290 & 3.880 & .000 \\
\hline & X3 & .509 & .082 & .532 & 6.202 & .000 \\
\hline & $\mathrm{X} 2$ & .050 & .047 & .102 & 1.054 & .293 \\
\hline
\end{tabular}

a. Dependent Variable: Y

Sumber : Hasil Penelitian, Diolah, 2020

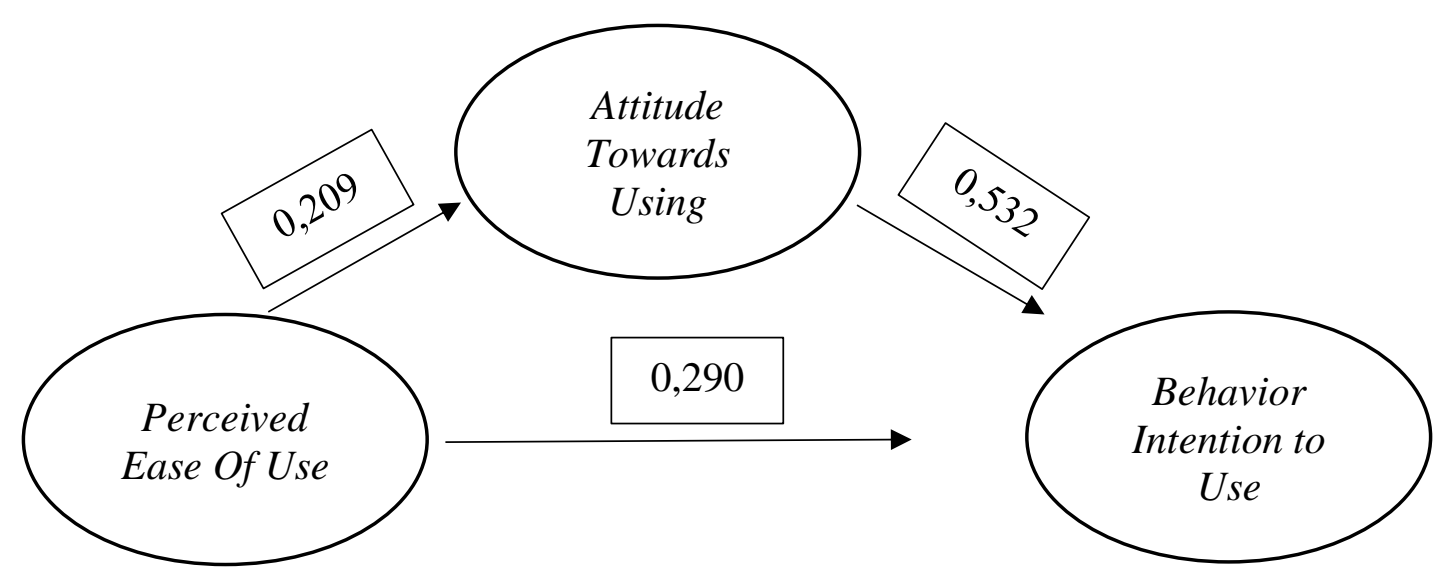

Gambar 2 


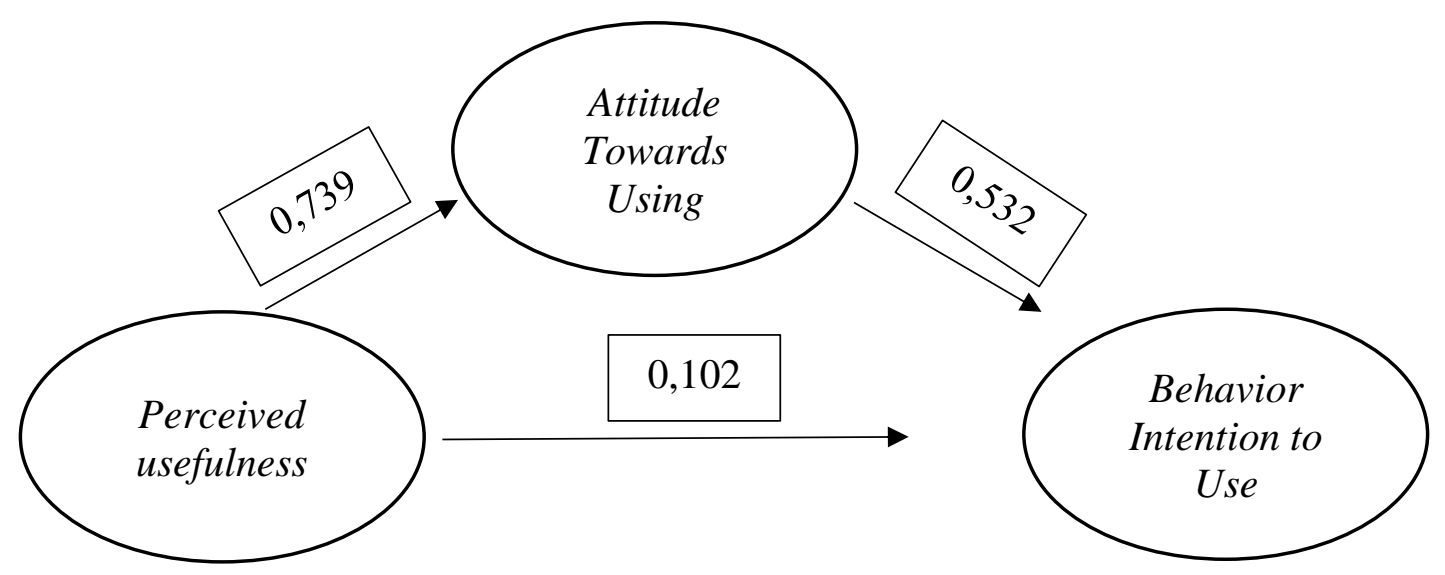

Gambar 3

\section{SIMPULAN DAN SARAN}

Simpulan dari penelitian ini adalah, bahwa perceived ease of use berpengaruh terhadap perceived usefulness, perceived ease of user berpengaruh siginifkan terhadap attitude, perceived usefulness berpengaruh terhadap attitude, perceived ease of use berpengaruh terhadap behavior intention to use, perceived usefulness berpengaruh terhadap behavior intention to use, attitude berpengaruh terhadap behavior intention to use. Attitude tidak memediasi perceived ease of use terhadap behavior intention to use. Attitude memediasi perceived usefulness terhadap behavior intention to use.

\section{DAFTAR PUSTAKA}

Ajeng, N. (2018). Analisis Faktor-Faktor Yang Mempengaruhi Minat Penggunaan T-Cash Pada Mahasiswa Universitas Islam Indonesia SKRIPSI Oleh: Nama No Mahasiswa: Ajeng Nurmalasari FAKULTAS EKONOMI UNIVERSITAS ISLAM INDONESIA YOGYAKARTA.

Bank Indonesia. (2014). Mengurangi Ketergantungan pada Uang Tunai. Gerai Info Bank Indonesia, 50, 4-5.

Chauhan, S. (2015). Acceptance of mobile by poor citizens of India: Integrating trust into the technology acceptance model. Emerald Insight, 17(3), 58-68. Retrieved from https://www.emerald.com/insight/content/do i/10.1108/info-02-2015-0018/full/html

Davis, F. D. (1989). Perceived usefulness, perceived ease of use, and user acceptance of information technology. MIS Quarterly: Management Information Systems, 13(3), 319-339. https://doi.org/10.2307/249008

Dewi Rachmat Kusuma. (2019). BUMN Resmi Luncurkan Aplikasi LinkAja. Retrieved from kumparan.com website: https://kumparan.com/kumparanbisnis/bumn -resmi-luncurkan-aplikasi-linkaja1rNV1vpouEF

Fishbein, M. (2014). The Influence of Attitudes on Behavior. (July).

Kompas. (2018). Perkembangan Industri Fintech di 2017 dalam Kacamata Asosiasi. Retrieved January 12, 2020, from Kompas.com website: https://ekonomi.kompas.com/read/2018/01/ 16/210000526/perkembangan-industri-fintechdi-2017-dalam-kacamata-asosiasi?page $=$ all

Mathieson, K. (1991). Comparing The Technology Acceptance Model with The Theory of Planned Behaviour. Information Systems Research, 2, 3(3), 173-191.

Rakhmad S, A., Astuti, E. S., \& Susilo, H. (2012). Pengaruh persepsi kemudahan dan persepsi kemanfaatan terhadap penggunaan youtube dengan pendekatan tam. Retrieved from https://media.neliti.com/media/publications/ 73685-ID-pengaruh-persepsi-kemudahan-danpersepsi.pdf

Sugiyono. (2013). Metode Penelitian Pendidikan Pendekatan Kuantitatif, Kualitatif, dan R\&DMetode Penelitian Pendidikan Pendekatan Kuantitatif, Kualitatif, dan R\&D. Bandung: Alfabeta.

Sugiyono. (2016). Metode Penelitian Kuantitatif, Kualitatif dan $R \& D$. Bandung: Alfabeta. 
Tatjana, A. (2016). Stakeholders' expectations of mobile payment in retail: lessons from Sweden.
International Journal of Bank Marketing, 34(1), 37. 